\title{
Laparoscopic cholecystectomy: first, do no harm; second, take care of bile duct stones
}

\author{
George Berci · John Hunter $\cdot$ Leon Morgenstern • Maurice Arregui • \\ Michael Brunt $\cdot$ Brandon Carroll $\cdot$ Michael Edye $\cdot$ David Fermelia \\ George Ferzli • Frederick Greene · Joseph Petelin • Edward Phillips • \\ Jeffrey Ponsky $\cdot$ Harry Sax $\cdot$ Steven Schwaitzberg $\cdot$ Nathaniel Soper $•$ \\ Lee Swanstrom $\cdot$ William Traverso
}

Received: 25 September 2012/Accepted: 18 November 2012/Published online: 26 January 2013

(C) Springer Science+Business Media New York 2013

The introduction of laparoscopic cholecystectomy (LC) in the USA in 1989 marked the beginning of what has become know as the "laparoscopic revolution" [1-4]. It was quickly adopted among surgeons in private practice. The Society of American Gastrointestinal Endoscopic Surgeons (SAGES) was the first organization to take the lead in ensuring patient safety by insisting on quality training through certified training courses, establishing guidelines, and introducing credentialing criteria for laparoscopic surgery. More than two decades later, it is time for SAGES to assume a leadership role in addressing two major and troublesome issues that remain in laparoscopic biliary surgery relating to patient safety and high-quality outcomes.

George Berci, John Hunter, and Leon Morgenstern contributed equally to the creation of this editorial.

G. Berci - L. Morgenstern - B. Carroll - D. Fermelia ·

E. Phillips · H. Sax

Cedars-Sinai Medical Center, Los Angeles, CA, USA

\section{J. Hunter $(\square)$}

Department of Surgery, L223, Oregon Health \& Science

University, 3181 SW Sam Jackson Park Road, Portland, OR 97239-3098, USA

e-mail: hunterj@ohsu.edu

\section{Arregui}

St. Vincent Hospital, Indianapolis, IN, USA

M. Brunt

Washington University, St. Louis, MO, USA

M. Edye

The Mount Sinai Hospital, New York, NY, USA

G. Ferzli

SUNY Health Science Center at Brooklyn, Staten Island,

NY 10304, USA

\section{Bile duct injury}

A bile duct injury (BDI) rate of $0.2 \%$ was reported in the era when open cholecystectomy (OC) was the standard [5]. Currently, LC BDI rates ranging from 0.2 to $0.5 \%$ are more the norm in large population-based studies [6-9]. Although the laparoscopic BDI rate may be lessening with the passage of time, BDI is still more likely with LC than with $\mathrm{OC}$, and remains a real danger in the learning curve of every surgeon [10]. After 25 years of LC, it appears that the risk of laparoscopic BDI is approximately twice what it was in the OC era. Even in the hands of competent surgeons, it is unlikely that BDI can ever be completely eliminated because inflammation and anatomic variation distort and obscure the anatomy. However, misidentifying

F. Greene

University of North Carolina School of Medicine, Charlotte,

NC 28207, USA

J. Petelin

Saint Lukes Health System, Kansas City, MO, USA

J. Ponsky

Case Western Reserve University, Cleveland, OH, USA

S. Schwaitzberg

Department of Surgery, Cambridge Health Alliance, Cambridge, MA, USA

N. Soper

Northwestern Memorial Hospital, Chicago, IL, USA

L. Swanstrom

The Oregon Clinic, Portland, OR, USA

W. Traverso

Virginia Mason Medical Center, Seattle, WA, USA 
the bile duct for the cystic duct in routine laparoscopic cholecystectomy remains a common mechanism of injury and should be largely preventable [11].

The magnitude of the problem in the USA can be calculated, as approximately 750,000 LCs are performed annually in the USA. If we accept that $0.4 \%$ of all LCs are associated with BDI, more than 3,000 patients will suffer a BDI every year [12-15]. The result is unnecessary acute pain, suffering, and additional operations, followed by chronic pain, disability, and litigation. Occasionally, liver transplantation is necessary. Mortality following BDI is $6 \%$ in the year after BDI, six times greater than the mortality of laparoscopic cholecystectomy without BDI [6]. In addition to the patient's and their family's lost income and productivity, there are unrecoverable costs to hospital systems, insurance carriers, the court system, and physicians. Lastly, the reputation of the involved surgeon, and surgeons in general, is tarnished each time a bile duct is injured.

The total costs of BDI in the USA each year can be estimated to exceed one billion dollars, half of which is absorbed in litigation, and the other half in care of the patient with BDI [16]. In these days of budgetary constraints in healthcare, we simply cannot afford preventable bile duct injuries. It should be a national priority to fund a comprehensive education program on BDI prevention, which should cost well less than the current costs of these injuries.

Strategies to eliminate BDI were promulgated in 1991, and have been refined over the years, as evidence has been gained to validate some of the original five principles [17]. These strategies can be divided into dissection and intraoperative imaging techniques.

\section{Dissection strategies}

Misidentification of the cystic duct is the most common cause of bile duct injury during laparoscopic cholecystectomy. The strategy developed in the era of open cholecystectomy, of restricting dissection to the wall of the gallbladder and dome-down dissection, has been the most effective one at preventing BDI. This is less easily performed laparoscopically, as disconnection of the gallbladder fundus from the liver early in the dissection adds an unnecessary degree of difficulty to the straightforward case [18]. Most surgeons start dissection on the infundibulum of the gallbladder, stripping peritoneum and fat circumferentially from the infundibulum until the cystic artery(s) are identified. This strategy, where the liver could be clearly visualized through Calot's triangle after complete dissection of the junction of gallbladder and cystic duct, was termed the critical view (CV) of safety in 1995 [14]. Evidence that the $\mathrm{CV}$ prevents biliary injuries comes primarily from two large studies that showed lower than expected rates of biliary injury when the $\mathrm{CV}$ method was used $[19,20]$.

\section{Intraoperative imaging strategies}

Intraoperative cholangiography (IOC) with fluoroscopy remains the most commonly used method for identifying intraoperative anatomy and assessing the common bile duct (CBD) for the presence of choledocholithiasis. Estimates vary, but in a recent population-based study, IOC was performed in $44.6 \%$ of all LCs [21]. This low utilization of IOC is a bit surprising, as there are substantial data demonstrating that IOC plays a significant role in prevention and detection of BDI [22-27]. In a meta-analysis of all the studies comparing BDI rates with and without cholangiography, it becomes apparent that BDI occurs twice as frequently when cholangiography is not performed as when it is performed [23]. The advocates for selective IOC create a strong argument that some patients may not need IOC [28], but to provide equivalent safety to a policy of routine IOC, at least $75 \%$ of all patients undergoing LC should have IOC [9].

If the safety benefits of cholangiography are so clear, why has there been no growth in its use in the last decade? Many surgeons feel the time taken is not well spent. The technique can be difficult, and reimbursement of the 10-20 min it takes to perform it and 0.5 relative value units (RVUs) for an IOC are paltry when considering the technical expertise and cognitive decision-making associated with the procedure. In addition, there is the dilemma of what to do if a bile duct stone is found on IOC. Most surgeons are not comfortable performing laparoscopic stone retrieval, and adding a duct exploration of unpredictable length can substantially slow down a busy operative list.

However, with no decrease in the number of biliary injuries after two decades of laparoscopic surgery and armed with the studies cited above, we advocate for an aggressive campaign to achieve duct injury mitigation (DIM).

Such a campaign should be three-armed and aimed at residents, fellows, practicing surgeons, and other trainees in postgraduate programs:

The first arm should be to teach standardized anatomic dissection and documentation of the hepatobiliary triangle that is agnostic to the surgical approach. Whether laparoscopic or open, four elements should be maintained:

(1) Clearance of all fat and fibrous tissue from the underside of the gallbladder fundus

(2) Separation of the lower gallbladder from the cystic plate (or gallbladder bed) 
(3) Demonstration and photo documentation of only one biliary structure entering the gallbladder

(4) Demonstration of the cystic artery branching onto the fundus of the gallbladder

The second arm is intensive training in the rationale and correct technique of intraoperative cholangiography which:

(1) Teaches the differing techniques of catheter insertion in the gallbladder or cystic duct

(2) Teaches how to set up, inject contrast, and perform both fluoroscopic (preferred) and static cholangiography

(3) Teaches the purpose of cholangiography, which:

(a) Delineates the anatomy of the biliary tree, disclosing variations and the presence or absence of stones or other abnormalities within the ducts

(b) Discloses BDI which otherwise might not have been detected during operation, thus permitting immediate repair or appropriate measures for delayed definitive correction

(c) Detects misidentification of the common duct (as the cystic duct) prior to incision, thus preventing a transection or an excisional injury to the common bile duct

Such training should include both surgical simulation to practice cannulation, and didactic instruction in the interpretation of IOC with special attention to recognition of variant anatomy. In the future, the indication for a cholangiogram should be cholecystectomy. IOC would then be routine, and not left to the discretion of each individual surgeon, who has many incentives to pass up IOC, despite the evidence that it improves patient care.

\section{Laparoscopic cholecystectomy and the common bile duct stone}

Surgeons who adopt routine IOC will find unsuspected common bile duct stones (CBDS) in $4 \%$ of their patients, and another 4-6\% will have CBDS suspected after reviewing the clinical data including jaundice, increased liver function tests (LFTs), hyperamylasemia, and/or an enlarged CBD, as seen with ultrasonography. For this reason we think it is important to include a third arm in DIM training: training in the techniques of laparoscopic cholecystectomy and bile duct exploration (LCBDE). Single-center, single-surgeon series demonstrate the efficiency gained with this strategy [29]. Several randomized clinical trials have addressed the proper management of CBD stones in association with LC [30-32]. In all of these studies, laparoscopic cholecystectomy and bile duct exploration decreased the duration of hospitalization when compared with endoscopic retrograde cholangiopancreatography (ERCP)/endoscopic sphincterotomy (ES) performed before or after LC. In addition, the cost was less when a single-stage procedure was utilized ( $\mathrm{LC}$ with bile duct exploration) compared with a two-stage procedure (ES before or after LC) [32, 33]. Other outcomes, such as duct clearance and complications, were equivalent between the two approaches.

There are many reasons given by surgeons who choose not to perform laparoscopic CBD exploration, but the most vexing is lack of adequate training in the technique of LCBDE. In a general surgery (GS) residency in the USA, the mean number of laparoscopic cholecystectomies performed was 112 in 2010 and 117 in 2011 [34]. If no ERCP/ ES were done in this population, one can calculate that the general surgery resident would explore 10-12 bile ducts in 5 years of training, or roughly 2-3 cases/year, hardly a sufficient exposure to become competent in LCBDE. Given these data, training for this rare event should be done in simulators, so the surgeon faced with a positive cholangiogram will not be unprepared, but will methodically prepare his/her equipment for laparoscopic CBDE, and perform the procedure with competence equivalent to one who performed LCBDE routinely. All residency programs in the USA have surgical skills laboratories, and most operating rooms have fluoroscopy available for wire basket stone retrieval or have small-caliber choledochoscopes or ureteroscopes available for choledochoscopy.

The time has come to return most of the CBD stones encountered during LC to surgical management in one setting. This may include allowing small stones to pass spontaneously. Laparoscopic exploration through the cystic duct or choledochotomy should be reintroduced into the domain of the operating surgeon by intensive training at all levels, both in the simulation laboratory as well as in the operating room. Familiarity with optimal IOC by its routine use will stimulate the surgeon to learn simple techniques to deal with the uncomplicated CBD stone(s), which are the majority of cases. Such action will contribute to improvement in patient care, safety, and quality of life and have a favorable impact on healthcare resources.

\section{Conclusions}

We propose an aggressive national education project that promotes standardized training in operative techniques, optimal use of proven imaging modalities during cholecystectomy, recognition of biliary and vascular anomalies, and training in laparoscopic common bile duct exploration in order to reduce bile duct injuries. It should be a national priority. If successful, this decade will become known as the duct injury mitigation era. 


\section{References}

1. Muhe E (1986) Die erste Cholecystectomy durch das Laparoskope [The first Cholecystectomy through the laparoscope]. Langenbecks Arch 369:804

2. Reddick E, Olsen D (1989) Laparoscopic laser cholecystectomy. Surg Endosc 3:131-133

3. Cuschieri A, Berci G (1990) Laparoscopic biliary surgery. Blackwell, London

4. Dubois F, Icard P, Berthelot G, Levard H (1990) Coelioscopic cholecystectomy. Ann Surg 211:60-62

5. Morgenstern L, Wong L, Berci G (1992) Twelve hundred open cholecystectomies before the laparoscopic era. Arch Surg 127:400-403

6. Sinha S, Hofman D, Stoker DL et al (2013) Epidemiological study of provision of cholecystectomy in England from 2000 to 2009: retrospective analysis of Hospital Episode Statistics. Surg Endosc 27(1):162-175

7. Harboe KM, Bardram L (2011) The quality of cholecystectomy in Denmark: outcome and risk factors for 20,307 patients from the national database. Surg Endosc 25(5):1630-1641

8. Waage A, Nilsson M (2006) Iatrogenic bile duct injury. Arch Surg 141:1207-1213

9. Flum DR, Patchen DE, Cheadle A et al (2003) Intraoperative cholangiography and risk of common bile duct injury during cholecystectomy. JAMA 289(13):164-1639

10. Archer SB, Brown DW, Smith CD et al (2001) Bile duct injury during laparoscopic cholecystectomy. Ann Surg 234(4):549-559

11. Davidoff AM, Pappas TN, Murray EA et al (1992) Mechanisms of major biliary injury during laparoscopic cholecystectomy. Ann Surg 215(3): 196-202

12. Woods MS, Traverso W, Kozarek RA et al (1994) Characteristics of biliary tract complications during laparoscopic cholecystectomy: a multi-institutional study. Am J Surg 167:27-33

13. Morgenstern L, McGrath MF, Carroll BJ et al (1995) Continuing hazards of the learning curve in laparoscopic cholecystectomy. Am Surg 61:914-918

14. Strasberg SM, Hertl M, Soper NJ (1995) An analysis of the problem of biliary injury during laparoscopic cholecystectomy. J Am Coll Surg 180:101-125

15. Flum DR, Koepsell T, Heagerty P et al (2001) Bile duct injury during laparoscopic cholecystectomy. Arch Surg 136:1287-1297

16. Carroll BJ, Birth M, Phillips EH (1998) Common bile duct injuries during laparoscopic cholecystectomy that result in litigation. Surg Endosc 12(4):310-313

17. Hunter JG (1991) Avoidance of bile duct injury during laparoscopic cholecystectomy. Am J Surg 162:71-76

18. Strasberg SM, Brunt LM (2010) Rationale and use of the critical view of safety in laparoscopic cholecystectomy. J Am Coll Surg 211:132-138

19. Averginos C, Kelgiorgi D, Touloumis $Z$ et al (2009) One thousand laparoscopic cholecystectomies in a single surgical unit using the "critical view of safety" technique. J Gastrointest Surg 13:498-503

20. Yegiyants S, Collins JC, Yegiyants S, Collins JC (2008) Operative strategy can reduce the incidence of major bile duct injury in laparoscopic cholecystectomy. Am Surg 74:985-987

21. Sheffield KM, Han Y, Kuo YF et al (2012) Variation in the use of intraoperative cholangiography during cholecystectomy. J Am Coll Surg 214:668-681

22. Phillips EH, Berci G, Carroll B et al (1990) The importance of intraoperative cholangiography during laparoscopic cholecystectomy. Am Surg 56:792-795

23. Ludwig K, Bernhardt J, Steffen H et al (2002) Contribution of intraoperative cholangiography to incidence and outcome of common bile duct injuries during laparoscopic cholecystectomy. Surg Endosc 16:1098-1104

24. Detry O, deRoover A, Detroz B et al (2003) The role of intraoperative cholangiography in detecting and preventing bile duct injury during laparoscopic cholecystectomy. Acta Chir Belg 103:161-162

25. Massarweh NN, Flum DR (2007) Role of intraoperative cholangiography in avoiding bile duct injury. J Am Coll Surg 204:656-664

26. Buddingh KT, Weersma RK, van Dam GM, Nieuwenhuijs VB (2011) Lower rate of major bile duct injury and increased intraoperative management of common bile duct stones after implementation of routine intraoperative cholangiography. J Am Coll Surg 213(2):267-274

27. Ausania F, Holmes LR, Ausania F et al (2012) Intraoperative cholangiography in the laparoscopic cholecystectomy era: why are we still debating? Surg Endosc 26:1193-1200

28. Misra M, Schiff J, Rendon G, Rothschild J, Schwaitzberg S (2005) Laparoscopic cholecystectomy after the learning curve: what should we expect? Surg Endosc 19:1266-1271

29. Petelin J (2003) Laparoscopic common bile duct exploration: lessons learned from $>12$ years of experience. Surg Endosc 17:1705-1715

30. Cuschieri A, Croce E, Faggioni A et al (1996) EAES ductal stone study. Preliminary findings of multicenter prospective randomized trial comparing two-stage vs single-stage management. Surg Endosc 10:1130-1135

31. Rhodes M, Sussman L, Cohen L, Lewis MP (1998) Randomised trial of laparoscopic exploration of common bile duct versus postoperative endoscopic retrograde cholangiography for common bile duct stones. Lancet 351:159-161

32. Rogers SJ, Cello JP, Horn JK et al (2010) Prospective randomized trial of LC + LCBDE vs ERCP/S + LC for common bile duct stone disease. Arch Surg 145(1):28-33

33. Urbach DR, Khajanchee YS, Jobe BA et al (2001) Cost-effective management of common bile duct stones. Surg Endosc 15:4-13

34. American Board of Surgery, Resident Case Log Data, 2010-2011 